\title{
Erratum to: A study of background radioactivity level for Canakkale, Turkey
}

\author{
Rustu Ilgar · Erol Kam • Ahmet Bozkurt
}

Published online: 13 March 2010

(C) Springer Science+Business Media B.V. 2009

\section{Erratum to: Environ Monit Assess \\ DOI 10.1007/s10661-009-1143-y}

In the original article, the sequence of authors was incorrect. The correct sequence should be Rustu Ilgar, Erol Kam and Ahmet Bozkurt.

The e-mail address for Rustu Ilgar was also incorrect. It should read: ilgar@mail.com.

The online version of the original article can be found at http://dx.doi.org/10.1007/s10661-009-1143-y.

\footnotetext{
R. Ilgar

Faculty of Education, Department of Geography Education, Canakkale Onsekiz Mart University, 17020 Canakkale, Turkey

e-mail: ilgar@mail.com

E. Kam

TAEK, Cekmece Nuclear Research and Training Centre, Altinsehir Yolu, 5. km, Halkali, 34303 Istanbul, Turkey e-mail: erolkam@hotmail.com

A. Bozkurt (四)

Faculty of Arts and Sciences, Department of Physics, Harran University, 63300 Sanliurfa, Turkey e-mail: bozkurt@harran.edu.tr
} 